\title{
Estudo comparativo de softwares de construção de tesauros
}

Maria Luiza de Almeida Campos

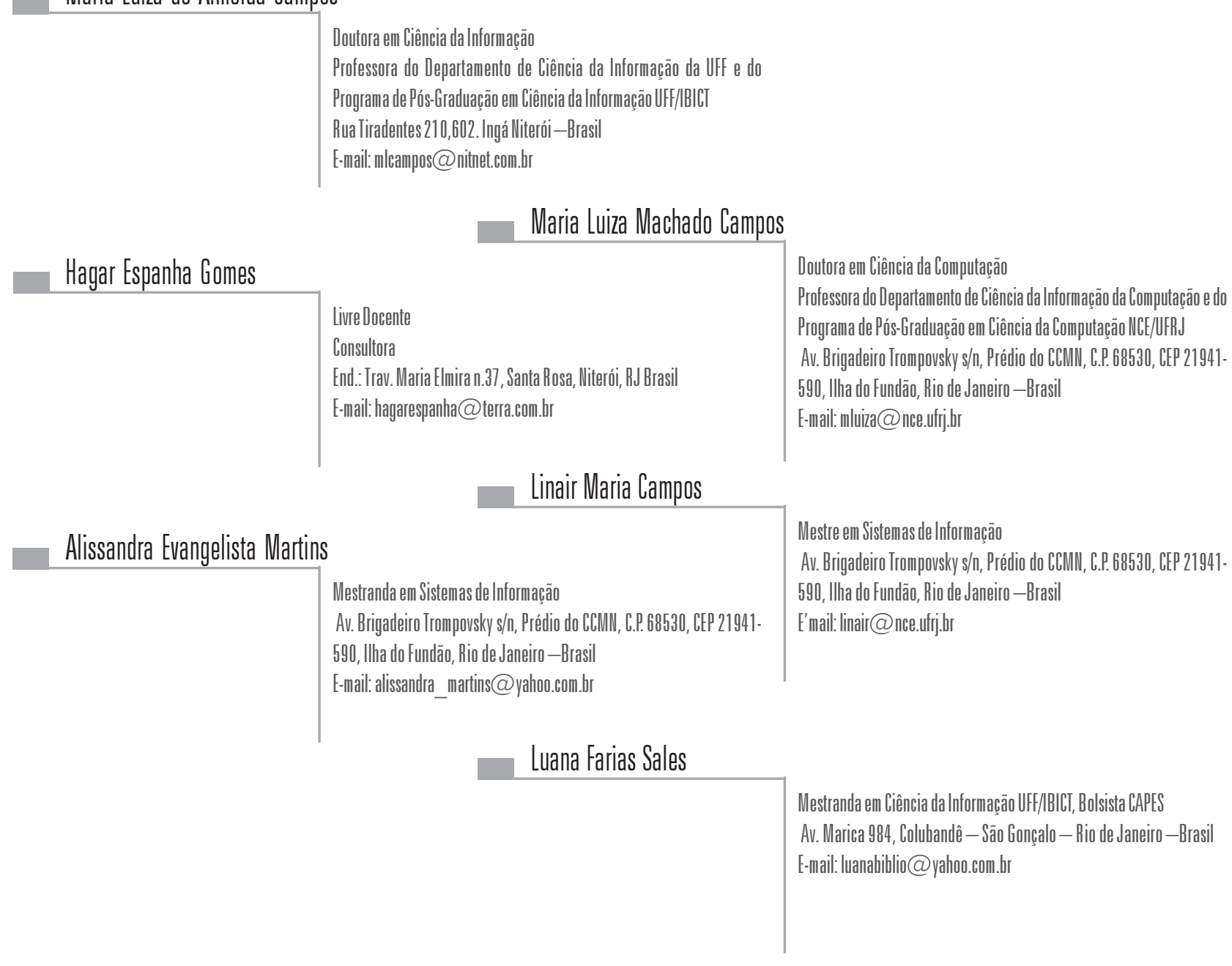

Para auxiliar a construção de vocabulários o uso e, conseqüentemente, a escolha de um software de construção de tesauros é uma necessidade. Entretanto, esses softwares possuem diferentes características de funcionalidades, custo e apoio metodológico, cuja análise criteriosa deve ser considerada, visando orientar a sua escolha de acordo com a finalidade e complexidade do tesauro a ser construído. Com base nessa necessidade de avaliação, o objetivo do presente trabalho é apresentar um estudo comparativo desses softwares, levando em consideração as utilizações dos tesauros nos dias de hoje.

Palavras-chaves: Softwares de tesauros; Avaliação de software Recebido em 25. I0.2005

Aceito em 20.03.2006 


\section{Introdução}

Com a difusão do uso dos computadores e das tecnologias de manipulação de documentos, surgiu a necessidade de organizar e recuperar a grande quantidade de informação a partir daí produzida, especialmente considerando o universo das grandes empresas, que muitas vezes disponibilizam diferentes tipos de dados através de uma rede corporativa, ou pela Internet. O objetivo é compartilhar os documentos de maneira rápida e fácil, deixando fluir o conhecimento do negócio, e, desta forma, a correta e eficiente recuperaçãa da informação tem se tornado vantagem competitiva para as corporações, na medida em que aumenta a sua produtividade (MILSTEAD, 1998). Nesse contexto, o uso de tesauros têm se destacado como ponto de apoio para a organização e acesso multifacetado da informação, bem como para a recuperação de conceitos relacionados.

Para auxiliar a construção desses vocabulários o uso de softwares de construção de tesauros é uma necessidade, devido às suas facilidades de armazenamento, manipulação e apresentaçãao dos termos definidos e suas relações. Desta forma, o objetivo dos tesauros e a escolha criteriosa de um software para sua implementação é importante caracterizar o que se entende por este instrumento e como pode se dar a sua elaboração.

Definir tesauro como uma linguagem documentária utilizada para recuperação de informação, de certa forma resume demais uma ferramenta que, entende-se e expande-se em aplicações, a partir da observação de seu histórico. Um século de história e aplicações explicam a importância de uma ferramenta que adequadamente construída com um suporte metodológico, torna-se um potente aliado na recuperação de informações.

A partir da década de 70 a Unesco apresenta definição para o instrumento tesauro que aponta dois aspectos de sua aplicaçãa, ou seja, aquele onde o tesauro é considerado como uma estrutura de termos relacionados semanticamente em dado contexto de conhecimento; e aquele onde se enfatiza sua função, isto é, um dispositivo de controle terminológico que visa o tratamento e a recuperação de informações.

É um vocabulário controlado e dinâmico de termos relacionados semântica e genericamente cobrindo um domínio específico do conhecimento... É um dispositivo de controle terminológico usado na tradução da linguagem natural dos documentos, dos indexadores ou dos usuários numa linguagem do sistema (linguagem de documentação, linguagem de informação) mais restrita. (UNESCO, 1973, p.6)

As questões enfrentadas pelos profissionais de informação são as mais variáveis possíveis e historicamente o resultado disso pode ser observado em uma divisão bastante clara das vertentes dos tesauros que surgem na América do Norte e na Europa. Após observar o diagrama evolutivo proposto por Lancaster (FIG. I), Campos (200 I) observa: $\bigcirc$ que fica evidente no diagrama é a dicotomia na linha evolutiva dos tesauros. De um lado, a vertente de abordagem alfabética, de grande influência na América do Norte, e, de outro, a abordagem sistemática, que tem seus pressupostos estabelecidos pela classificação facetada. (CAMPOS, 200 I) 
O diagrama de Lancaster ilustra a evolução dos tesauros de vertente alfabética (linha americana) e dos tesauros que usam a abordagem sistemática (linha européia), porém, devido à sua representação estar contextualizada em dado período histórico de sua evolução, ainda não evidencia o surgimento do tesauro de origem conceitual, para o qual a definição do conceito é requisito fundamental. Este tipo de tesauro surge no contexo de estudos derivados das teorias do conceito (DAHLBERG, 1978) e da teoria da classificação facetada ( 1967), sendo caracterizado com mais detalhes na seção 3.

No processo de elaboração de software de tesauros há que se levar em conta os aspectos metodológicos, os quais variam de acordo com a linha adotada para a sua construção, e também outros aspectos operacionais independentes da metodologia adotada, como por exemplo, mecanismos para a criação e controle de atualização de termos, possibilidade de reutilização de outros tesauros e elaboração de relatórios.

Considerando essas características, podemos afirmar que a construção de um tesauro não é uma tarefa trivial e que para o seu projeto é importante o uso de uma ferramenta de software que apóie não só as questões operacionais, mas também a metodologia usada para a sua elaboração. Este trabalho pretende apontar as funcionalidades que tal ferramenta deve ter para que possa atender aos requisitos identificados, bem como avaliar as ferramentas já existentes, à luz desses requisitos. Além disso, os atributos são agrupados em categorias, o que permite uma avaliação objetiva.

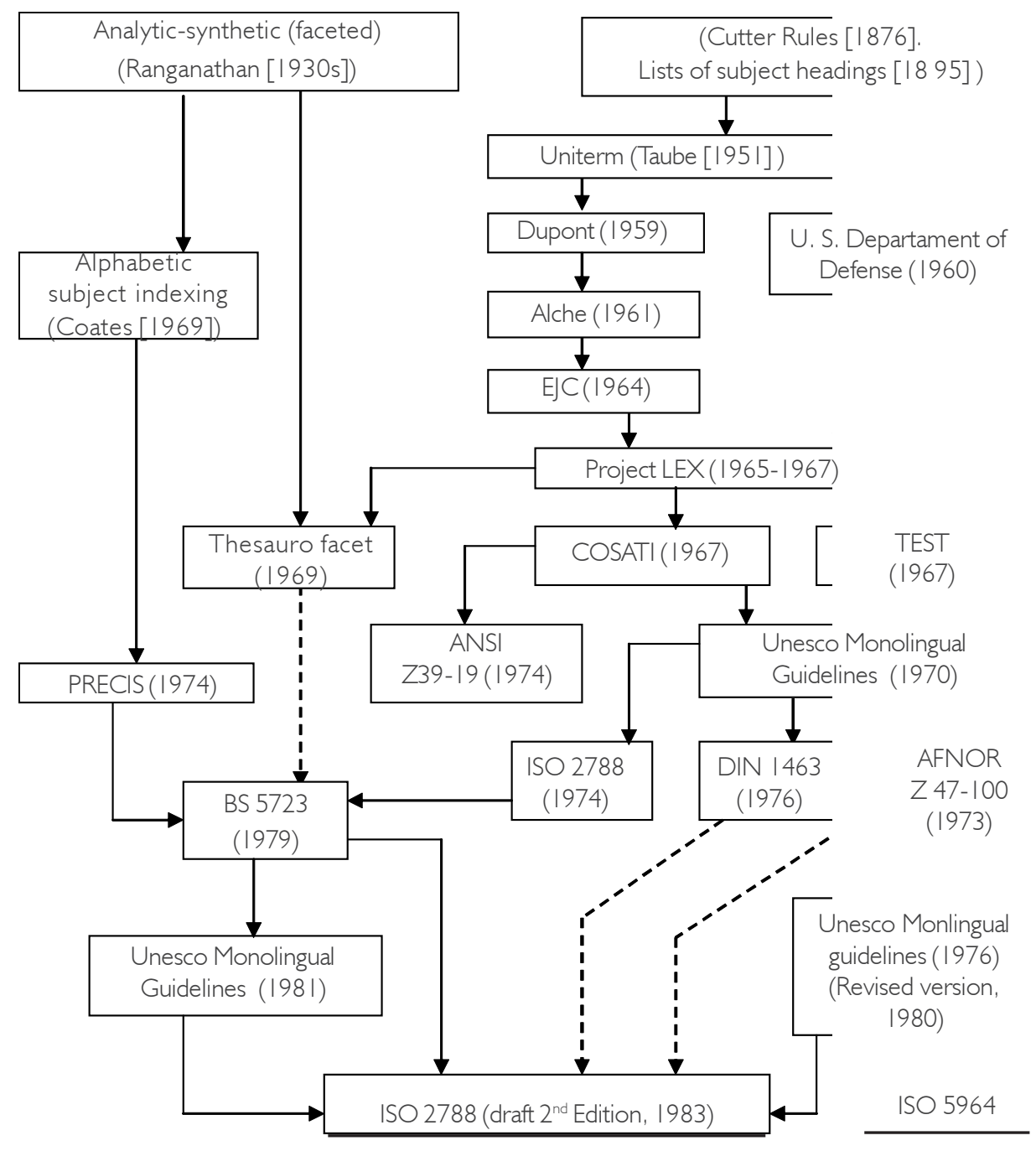

FIG. I : Diagrama evolutivo dos tesauros (LANCASTER, 1986, p.30) 


\section{Utilização de tesauro}

Tesauros têm sido utilizados para indexar e recuperar informação em diversos domínios, tais como: ciência da informação, mecatrônica, folclore, jurídico. Sua estrutura fornece um vocabulário uniforme para indexar a informação e permite aos seus usuários uma forma intuitiva e organizada de pesquisar assuntos de seu interesse, muitas vezes em mais de uma língua, como por exemplo, no General European Multilingual Environment Thesaurus (GEMET, 2005).

Além de seu uso para indexação de assuntos, o tesauro pode ainda oferecer outros recursos, através da exploração das relações entre seus termos, através de notas de escopo, ou outras informações, tal como a origem do termo.

Nesse contexto, a eficiência do uso de tesauros tem sido comprovada em estudos que apontam para ganhos de precisão nas consultas da ordem de 30\% (SILVEIRA, 2003) e seu uso tem se difundido, passando da indexação de acervos de bibliotecas por meio de fichas catalográficas em papel, até a indexação de acervos multimídia digitais. É importante ressaltar que a forma de elaboração do tesauro vai influir na sua eficiência. Por exemplo, um tesauro pode ter poucas relações associativas' entre os termos, dificultando o resgate de termos correlatos. Questões dessa natureza remetem a aspectos metodológicos, que são abordados na seção seguinte.

\section{Metodologia para construção de tesauro}

Os tesauros americanos que seguem a vertente alfabética foram fruto do desenvolvimento que ocorreu a partir do cabeçalho de assuntos para o unitermo (CAMPOS, 200 I ). Essa linha de evolução privilegia a criação de termos pelo seu sentido lingüístico, não utilizando bases classificatórias ou terminológicas para a determinação do termo e suas relações. Conseqüentemente, neste tipo de tesauro não existe a preocupação de se criar categorias para agrupar os termos que possuam atributos comuns, sendo a lista alfabética a única forma de recuperação de informação.

Os tesauros que seguem a vertente européia utilizam categorias para organizar os termos. Esta vertente foi influenciada pela teoria da classificação facetada de Ranganathan ( 1967). $\bigcirc$ uso de facetas facilita evidenciar as relações entre os termos e a navegação pelo tesauro. Dessa forma, passa a ser possível buscar um assunto percorrendo as diversas facetas criadas, de forma sistemática, o que é uma vantagem quando não se sabe a priori o termo desejado, especialmente em tesauros com muitos termos.

Apesar desta vertente avançar quanto aos aspectos relacionados a uma apresentação sistemática do tesauro, seus autores apresentam um comportamento semelhante ao dos autores americanos no que se refere ao estabelecimento do termo propriamente dito, ou seja, ainda se privilegia o sentido lingüístico na sua criação.

De acordo com Campos (200 I), verifica-se atualmente, devido à corrente que liga a teoria do conceito à teoria da classificação, uma tendência para um novo tipo de tesauro, o tesauro conceitual. Este é um tesauro com base em conceitos, onde na sua construção são necessários princípios para o
' Relação Associativa é uma relação nãohieráquica entre conceitos e classes (WERSIG, NEVELING, 1976) 
estabelecimento do termo/conceito e das relações entre eles. Neste tipo de tesauro o sentido lingüístico não é mais determinante na criação e organização dos termos e sim o seu conteúdo conceitual.

É importante observar que as linhas de elaboração de tesauros possuem aspectos divergentes. Entretanto, apesar de suas particularidades, elas partilham de alguns requisitos comuns. Em todas as três tem-se a necessidade de se fazer um levantamento do escopo do domínio a ser representado, as relações entre os termos e suas sinonímias.

A linha européia e a linha do tesauro conceitual consideram os aspectos de categorização dos termos, ou seja, sua organização e apresentação sistemática (GOMES, CAMPOS, MOTTA, 2004). Esta organização pode influenciar no estabelecimento das relações entre os termos, por exemplo, pode limitar que relações do tipo gênero/espécie se dêem entre termos de categorias distintas. Porém, apenas no tesauro conceitual existe a preocupação com a definição do conceito que, por sua vez, vai influenciar a maneira da organização dos termos em categorias. A TAB. I ilustra esses aspectos.

TABELA I - Aspectos Metodológicos das Linhas de Construção de Tesauro

\begin{tabular}{|c|c|c|c|c|}
\hline Linhas/Aspectos & $\begin{array}{c}\text { Levantamento do } \\
\text { Escopo }\end{array}$ & $\begin{array}{c}\text { Relações entre } \\
\text { termos }\end{array}$ & Categorização & $\begin{array}{c}\text { Definição do } \\
\text { conceito }\end{array}$ \\
\hline Americana & $\operatorname{Sim}$ & $\operatorname{Sim}$ & Não & Não \\
\hline Européia & $\operatorname{Sim}$ & $\operatorname{Sim}$ & $\operatorname{Sim}$ & Não \\
\hline Conceitual & $\operatorname{Sim}$ & $\operatorname{Sim}$ & $\operatorname{Sim}$ & $\operatorname{Sim}$ \\
\hline
\end{tabular}

Além dos aspectos comuns e divergentes envolvidos nas metodologias, há que se considerar que a construção de um tesauro é um projeto que na maior parte das vezes envolve uma equipe multidisciplinar, composta por profissionais com o conhecimento do domínio a ser representado e profissionais com o conhecimento sobre como modelar um domínio, estes últimos geralmente oriundos da área de ciência da informação. Pode-se ainda acrescentar que a construção de um tesauro está sujeita a fatores semelhantes aos que ocorrem no desenvolvimento de um projeto de software, tais como: levantamento de requisitos, modelagem do problema, controle de versões e manutenção. Tendo em mente esses aspectos, na seção seguinte discutimos os requisitos propostos para a construção de tesauros.

\section{Trabalhos relacionados}

Existem algumas iniciativas que apontam características desejáveis em um tesauro. Dentre elas temos as normas internacionais, ilustradas na FIG. I, e ainda outros estudos, como os de Gomes, Campos, Motta, (2004) e o de Soergel, (2002), que apontam características tais como: padrão para denominação de termos, tipos de relação entre termos, regras para atualização do tesauro, dentre outras. Como se espera que os softwares de tesauro contemplem essas características, elas podem ser consideradas para o 
levantamento de alguns dos requisitos desses softwares. Entretanto, alguns aspectos não dizem respeito às características do tesauro em si, e sim à implementação do software, e não são considerados por estas iniciativas. Por exemplo: se o software é livre e gratuito, se roda em vários tipos de sistemas operacionais, se possui interface Web, dentre outras. Além disso, não é do escopo das iniciativas supracitadas a comparação de softwares de tesauro.

Neste contexto, o trabalho de Ganzmann (1990) é o mais detalhado que encontramos, apresentando uma lista de características bastante abrangente, cobrindo aspectos que vão desde a ergonomia do software até construção de relações multilingües entre os termos. Entretanto, alguns dos aspectos levantados por Ganzmann já se encontram obsoletos devido à data de sua publicação.

Por outro lado, mesmo propondo uma lista detalhada, alguns aspectos não foram abordados, como por exemplo, questões relacionadas à metodologia de construção do tesauro, notadamente nas fases que estão relacionadas a análise do domínio e seu planejamento.

Nesse sentido, até onde temos notícia, não há trabalho publicado que leva em consideração essa visão integrada (características ligadas ao tesauro e ao software), e ainda, que a utiliza para fazer uma comparação dos softwares de tesauro. Na verdade, não encontramos qualquer iniciativa de comparação de softwares de tesauro publicada. $\bigcirc$ trabalho que mais se aproxima neste sentido é o de Will (2005). Nesse trabalho o autor faz apenas referências a princípios para elaboração de tesauros e, independente destes, faz um quadro onde analisa vários softwares de tesauro. Além disso, a análise dos softwares não é feita de forma sistemática, ou seja, não segue um quadro de referência onde cada aspecto é avaliado para todos os softwares considerados. A análise é feita em forma de texto resumido, onde para cada software há informações básicas sobre os recursos que ele oferece, juntamente com informações de contato e, quando pertinente, da página Web do software ou da instituição que o fornece. Por outro lado, não há na iniciativa de Will uma forma objetiva de se obter uma medida de avaliação de softwares. Neste sentido, a contribuição principal de nosso trabalho é a apresentação de um levantamento ponderado dos requisitos que um software de tesauro deve possuir, levando em consideração os aspectos metodológicos que influem na sua elaboração, bem como as suas características operacionais e de implementação.

\section{Requisitos dos softwares de construção de tesauro}

levantamento de requisitos partiu de uma revisão dos trabalhos de Ganzmann (1990) e Gomes, Campos e Motta (2004), bem como da norma ISO 5964 (1985), onde os critérios propostos pelos autores foram analisados sob a perspectiva da tecnologia atual, sumarizados para permitir uma comparação mais objetiva, e estendidos para incluir aspectos metodológicos. Para facilitar esse repensar do levantamento de requisitos, vamos denominar doravante de critérios os requisitos originalmente propostos pelos autores e de requisitos os que foram reformulados no contexto deste trabalho.

Desta forma, critérios muito detalhados como: não permitir a entrada duplicada de termos, controle de relaçóes ilógicas entre níveis 
hierárquicos, não permitir relações duplicadas entre dois termos, foram resumidos para o requisito consistência. Cabe ressaltar que o fato de terem sido sumarizados, não implica em que seu detalhamento tenha sido ignorado ao avaliar o software. Ou seja, se um desses critérios específicos não é atendido, considera-se que o software não atende ao requisito em questão, porém na tabela comparativa dos softwares (Seção 6), é exibido apenas o requisito resumido.

Critérios já ultrapassados foram desconsiderados, como por exemplo, o uso do mouse como fator de ergonomia, pois hoje em dia o uso do mouse já está consolidado nos softwares de um modo geral. Critérios difíceis de avaliar de forma objetiva foram desconsiderados para facilitar a avaliação, como, por exemplo, os diferentes tipos de mensagem (erro, alerta, confirmação, dentre outras) contribuindo para a ergonomia do software. Neste caso, a ergonomia foi avaliada sob outros enfoques, tais como: facilidade de uso, ou seja, se o usuário é capaz de criar um pequeno conjunto de termos e suas relações sem auxílio de documentação. Embora esse requisito também possua algum grau de subjetividade, sua avaliação restringe-se a sim ou não, ao contrário das mensagens, onde não fica claro em que situação o software é considerado ergonômico ou não.

objetivo é prover um conjunto mínimo de requisitos que se espera sejam atendidos por um software de tesauro, e classificá-los de acordo com seu grau de importância. Estes graus se dividem em essenciais, importantes e inovadores. Essenciais são os requisitos que o software deve atender para ser considerado adequado, e, portanto, seu peso deve ser pelo menos maior que a soma dos outros (em nosso trabalho adotamos o valor 50). Importantes são os requisitos que acrescentam funcionalidades além das essenciais ao software, tornando-o mais fácil de usar, e possuem peso I. Inovadores são requisitos que destacam o software dentre os demais, fornecendo funcionalidades que contribuem de forma original para a elaboração do tesauro, e possuem peso 3. É importante ressaltar que os pesos podem variar, de acordo com a perspectiva de cada avaliador. Por exemplo, o fator custo gratuito pode ser considerado de peso 50 para uma empresa que não esteja disposta a investir na compra de um produto, mas pode ter peso I para uma outra que deseje priorizar as funcionalidades do software. Dessa forma, os pesos aqui sugeridos podem ser adaptados a situações específicas, de acordo com a necessidade. $\bigcirc$ importante é que a sua atribuição permite obter uma avaliação objetiva do software ao final. $\bigcirc$ peso de cada requisito é indicado entre parêntesis, à direita de cada critério na TAB. 2.

Partindo do exposto, os requisitos considerados são divididos em oito grupos, a saber:

\section{a) Características gerais}

Em características gerais temos a avaliação de requisitos genéricos que são importantes para a construção dos termos de tesauro. Nesta categoria se enquadram as limitações genéricas (restrição de tamanho, número, de termos e possibilidade de uso de termos compostos, a existência da informação da fonte ou origem do termo, a possibilidade de criar classes de assuntos, e se os termos podem ser expressos em mais de um idioma.) 


\section{b) Tratamento de relações}

Em tratamento de relaçóes, estão os requisitos que indicam de que forma o software permite conceber as relações entre os termos, ou seja, se o software permite relações definidas pelo usuário, relações padrão e relações adotadas no padrão ISO 5964 ( | 985).

\section{c) Tratamento de dados}

Em tratamento de dados, estão os requisitos que indicam de que forma se dá o armazenamento e a aquisição dos dados, ou seja, se o software permite guardar o tesauro em banco de dados, se permite importação de termos de e para outras fontes, se existe crítica em relação à consistência de dados, se é feito algum controle de restrição de acesso para atualização do tesauro e se permite o gerenciamento da situação de termos, como por exemplo, termos candidatos ou termos obsoletos.

\section{d) Interface / Manipulação dos dados}

Em interface / manipulação dos dados, os requisitos estão voltados para avaliar a maneira que o software permite interagir com os seus usuários, tanto no projeto do tesauro quanto na pesquisa, ou seja, se permite busca flexível por termos, se permite reorganizar a hierarquia de termos, se possui interface Web, e se a criação do tesauro é um processo intuitivo.

\section{e) Relatórios}

Em relatórios, estão os requisitos voltados para avaliar a apresentação da estrutura do tesauro ao usuário final, ou seja, que tipos de relatório possuem, dentre os seguintes: alfabético, sistemático, KWIC, hierárquico e definido pelo usuário.

\section{f) Características de implementação}

Em características de implementação, os requisitos têm como objetivo avaliar os pré-requisitos que o software possui para ser utilizado, ou seja, se depende de software não livre, se roda em Unix, se roda em Windows e se é gratuito.

\section{g) Apoio metodológico}

Em apoio metodológico, os requisitos buscam avaliar se o software foi projetado com recursos que forneçam apoio ao uso de alguma metodologia de construção de tesauros, ou seja, recursos que apóiem os aspectos ilustrados na TAB. I. Esses requisitos são: representação gráfica do escopo ajuda estabelecer o relacionamento entre termos, categorização com base no conceito e uso de características de divisão - que permitem agrupar termos de uma mesma hierarquia de acordo com algum atributo comum (GOMES, CAMPOS, MOTTA, 2004). Cabe ressaltar que este 
último requisito, diz respeito à etapa de categorização de termos do tesauro.

\section{Apoio ao uso}

Em apoio ao uso, os requisitos estão voltados para avaliar o tipo de apoio que o fabricante do software disponibiliza aos seus clientes na utilização do produto, ou seja, se o software possui: suporte, grupo de usuários ativo, ajuda online e documentação.

\section{Comparação de softwares de construção de tesauros}

Os softwares selecionados foram obtidos a partir de pesquisa na Internet. São eles: Term Choir (2005), Multites (2005), TheSmain (2005), TermTree (2005), Synaptica(2005) e TemaTres (2005).

Alguns dos softwares possuem cópias de demonstração, que foram instaladas e utilizadas para a construção de um pequeno tesauro, a título de teste. Dentre esses, alguns apresentaram problemas na instalação, os quais não foram solucionados. Outros não possuem cópia de demonstração. Sendo assim, com exceção do primeiro grupo, os outros softwares foram avaliados com base em material disponível na página web do produto. Os softwares avaliados através de documentação são indicados por um asterisco ao lado do seu nome.

Foram desconsiderados softwares que não possuem versão para windows 2000 ou superior ou então algum tipo de linux ou unix e ainda os que apresentaram problemas na instalação. A escolha dos seis softwares listados se deve ao resultado de uma análise preliminar, onde foram selecionados aqueles cujo conjunto de funcionalidades foi considerado suficiente para esse estudo comparativo. A exceção é o software TemaTres, que, apesar de apresentar poucos recursos, foi selecionado por ser o mais completo dentre os softwares livres avaliados.

A avaliação da TAB. 2 permite concluir que, de uma maneira geral, os softwares de tesauro atendem de maneira satisfatória a maioria dos requisitos que estes devem ter, exceto pelos aspectos metodológicos. Sendo assim, têm-se as seguintes observações.

\section{a) Características gerais}

Em relação às características gerais, podemos observar que os softwares não gratuitos as atendem de forma bastante abrangente. De todos os avaliados, apenas o TermTree possui uma restrição: não é multilingue, o que pode ser uma limitação séria, dependendo do propósito do tesauro. Já o TemaTres, gratuito, não possui capacidade para referenciar a fonte do termo, embora seja multilingue.

\section{b) Tratamento de relações}

Em relação ao tratamento de relações, observamos que Thesmain, TermTreee TemaTres não permitem a criação de relações definidas pelo usuário. Esta limitação pode ser um problema no caso de se querer fornecer alguma 
semântica adicional ao tesauro, como por exemplo, a caracterização de diferentes tipos de relações partitivas. Além disso, neste item, temos que a maioria dos softwares segue padrões mais antigos como o Z39-19 ( I 974), enquanto que o padrão ISO 5964 (1985) é utilizado apenas pelo ThesMain.

\section{c) Tratamento de dados}

Em relação ao requisito tratamento de dados, podemos verificar que é atendido de maneira integral pelos softwares não gratuitos. $\bigcirc$ TemaTres, por outro lado, não permite importação nem controle de atualização dos dados. Estes aspectos podem ter um impacto profundo na construção de tesauros de maior porte, onde não só a reutilização de termos de outras fontes, como também o controle de sua atualização é de grande importância, fazendo com que a solução gratuita não seja adequada.

\section{d) Interface e manipulação de dados}

Em relação ao requisito interface e manipulação de dados, podemos afirmar que ele é atendido de maneira adequada em relação à facilidade de uso e busca flexível, que, pode-se considerar como os recursos mais importantes. Entretanto, a reorganização de hierarquias, que pode ser importante para tesauros muito grandes ou que mudam com muita freqüência, só é atendida pelos softwares TermChoir e TremTree. O recurso interface Web, também não é atendido pelos softwares Multites e ThesMain, o que pode ser um problema no caso de se querer disponibilizar - acesso remoto a pessoas autorizadas a manipular o tesauro, ou no caso de a política de instalação de softwares da empresa estar voltada para o uso de softwares através da Web.

\section{e) Emissão de relatórios}

Em relação à emissão de relatórios, ela é, de um modo geral, bem explorada pelos softwares não gratuitos, inclusive em relação a relatórios na Web, onde apenas o ThesMain não oferece. Já o TemaTres, gratuito, oferece grandes limitações nesse aspecto, permitindo apenas o relatório alfabético.

\section{f) Características de implementação}

Em relação às características de implementação observamos sérias restrições em relação a softwares não proprietários. Apesar de apenas o Multites e o ThesMain não rodarem em ambientes baseados em Unix, todos os softwares não gratuitos avaliados dependem de algum software não livre, como por exemplo banco de dados da Oracle (2005) ou da Microsoft (2005). Em contrapartida, o software livre gratuito é bem inferior em relação aos demais. Esta é uma limitação das mais sérias, pois pode ir contra a política de software da empresa, especialmente se a empresa é pública, pois existe a atualmente a orientação crescente de se adotar softwares livres nestas instituições. 


\section{g) Aspectos metodológicos}

Em relação aos aspectos metodológicos, nenhum dos softwares disponíveis possui apoio abrangente, ou seja, nenhum deles relaciona as etapas de utilização do software à uma base teórica-metodológica para construção de tesauros, ainda que possuam ferramentais que auxiliem na adoção de uma metodologia. Um exemplo de ferramental que pode servir como auxiliador é a ajuda na definição dos conceitos através da busca Web, por parte dos softwares Synaptica e TermChoir.

\section{h) Apoio ao uso}

Em relação ao requisito de apoio ao uso, pode-se dizer que ele também é atendido de maneira geral pelos softwares não livres, exceto no aspecto de grupos de usuários ativos, o qual nenhum dos softwares possui, o que caracteriza possivelmente a pouca maturidade de uso dessas ferramentas.

Podemos observar também que poucos softwares possuem um conjunto relevante de características inovadoras. Dentre as nove possíveis, TermChoir e Synaptica possuem três, Multites e TermTree possuem duas, ThesMain e TemaTres possuem apenas uma.

TABELA. 2 - Comparativo de softwares de construção de tesauro

\begin{tabular}{|c|c|c|c|c|c|c|c|c|}
\hline & & Critério & TemChoir & Multites & $\begin{array}{c}\text { TheSmain } \\
\text { [Superthes }\end{array}$ & \begin{tabular}{|c|} 
TermTree \\
2000
\end{tabular} & Sgnaptica" & |TemaTres" \\
\hline \multirow{4}{*}{1} & 1.1 & Limitaçổes genéricas (50) & กão & กล̃o & nẫo & nẫo & não & กão \\
\hline & 1.2 & Fonte do termo [1] & $\operatorname{sim}$ & $\sin$ & $\operatorname{sim}$ & $\operatorname{sim}$ & $\operatorname{sim}$ & nao \\
\hline & 1.3 & Classes de assunto (1) & $\sin$ & $\sin$ & $\sin$ & $\sin$ & $\sin$ & nao \\
\hline & 1.4 & Multilinqüie [1] & sim & $\operatorname{sim}$ & $\operatorname{sim}$ & não & $\operatorname{sim}$ & $\operatorname{sim}$ \\
\hline \multirow{3}{*}{2} & 2.1 & Relaçôes definidas pelo usuário [50] & $\operatorname{sim}$ & $\operatorname{sim}$ & não & não & $\operatorname{sim}$ & nao \\
\hline & 2.2 & Relaçổes padrão [1] & $\operatorname{sim}$ & sim & $\operatorname{sim}$ & $\sin$ & $\operatorname{sim}$ & $\operatorname{sim}$ \\
\hline & 2.3 & Padrăo ISO 5964 [1] & não & กล๊̃o & $\operatorname{sim}$ & não & กั̃o & กล̃o \\
\hline \multirow[t]{6}{*}{3} & 3.1 & Persistência em banco de dados (50) & $\operatorname{sim}$ & $\operatorname{sim}$ & $\operatorname{sim}$ & $\operatorname{sim}$ & $\operatorname{sim}$ & $\operatorname{sim}$ \\
\hline & 3.2 & Importac:äo de dados (1) & $\operatorname{sim}$ & $\sin$ & $\sin$ & $\sin$ & $\sin$ & กล̊̃o \\
\hline & 3.3 & Exportacazo de dados (1) & $\sin$ & $\operatorname{sim}$ & $\sin$ & $\sin$ & $\sin$ & $\sin$ \\
\hline & 3.4 & Consistềncia (50) & $\operatorname{sim}$ & $\operatorname{sim}$ & $\operatorname{sim}$ & $\operatorname{sim}$ & $\operatorname{sim}$ & $\operatorname{sim}$ \\
\hline & 3.5 & Controle de Acesso (1) & sim & sim & $\operatorname{sim}$ & sim & $\operatorname{sim}$ & sim \\
\hline & 3.6 & \begin{tabular}{|l} 
Controle de Atualizaçăo de Dados (1) \\
\end{tabular} & $\operatorname{sim}$ & $\operatorname{sim}$ & sim & $\operatorname{sim}$ & $\operatorname{sim}$ & กล̃̃o \\
\hline \multirow{4}{*}{4} & 4.1 & Busca Flesível (1) & $\operatorname{sim}$ & $\operatorname{sim}$ & $\sin$ & $\operatorname{sim}$ & $\sin$ & $\operatorname{sim}$ \\
\hline & 4.2 & Recursos para reorganizar hierarquias [1] & $\operatorname{sim}$ & กั๊o & กă๊o & $\operatorname{sim}$ & กã๊o & กล๊̃o \\
\hline & 4.3 & Facilidade de uso (1) & sim & $\operatorname{sim}$ & sim & $\operatorname{sim}$ & $\operatorname{sim}$ & $\operatorname{sim}$ \\
\hline & 4.4 & Interface Yeb [1] & $\operatorname{sim}$ & não & กิ๊̃o & $\operatorname{sim}$ & $\operatorname{sim}$ & $\operatorname{sim}$ \\
\hline \multirow{6}{*}{5} & 5.1 & Relatório Alfabético [1] & sim & sim & sim & sim & sim & sim \\
\hline & 5.2 & Relatório Sistemático [1] & $\sin$ & $\operatorname{sim}$ & $\sin$ & $\sin$ & $\sin$ & กร๊̃o \\
\hline & 5.3 & Relatório KVIC (1) & sim & $\operatorname{sim}$ & $\operatorname{sim}$ & $\operatorname{sim}$ & กล̃o & กã̃o \\
\hline & 5.4 & Relatório Hierárquico [1] & sim & $\operatorname{sim}$ & sim & $\operatorname{sim}$ & sim & กão \\
\hline & 5.5 & Relatórios na web (1) & sim & $\operatorname{sim}$ & กão & sim & $\operatorname{sim}$ & กล̃o \\
\hline & 5.6 & Relatório definido pelo usuário [3] & $\operatorname{sim}$ & $\operatorname{sim}$ & $\operatorname{sim}$ & $\operatorname{sim}$ & $\operatorname{sim}$ & กล๊̃o \\
\hline \multirow{4}{*}{6} & 6.1 & Depende de Software näo Livre (3) & $\operatorname{sim}$ & $\operatorname{sim}$ & $\operatorname{sim}$ & $\operatorname{sim}$ & $\operatorname{sim}$ & กão \\
\hline & 6.2 & Roda em Unix [1] & $\operatorname{sim}$ & กล๊̃o & กẫo & $\operatorname{sim}$ & $\operatorname{sim}$ & $\operatorname{sim}$ \\
\hline & 6.3 & Roda em Yindows [1] & $\operatorname{sim}$ & $\operatorname{sim}$ & $\operatorname{sim}$ & $\operatorname{sim}$ & $\operatorname{sim}$ & $\operatorname{sim}$ \\
\hline & 6.4 & Gratuito [3] & กẫo & กẫo & กão & กã̃o & nẫo & $\operatorname{sim}$ \\
\hline \multirow{4}{*}{7} & 7.1 & Possui suporte [3] & $\operatorname{sim}$ & $\operatorname{sim}$ & กว̃o & $\operatorname{sim}$ & sim & กล๊̃o \\
\hline & 7.2 & Possui grupo de usuários ativo [3] & กẫo & กẫo & กẫo & กẫo & กã̃o & กã̃o \\
\hline & 7.3 & Possui ajuda online (1) & $\operatorname{sim}$ & $\operatorname{sim}$ & $\operatorname{sim}$ & $\operatorname{sim}$ & $\operatorname{sim}$ & กล̃̃o \\
\hline & 7.4 & \begin{tabular}{|l} 
Possui documentacaáo [1] \\
\end{tabular} & sim & $\operatorname{sim}$ & sim & $\operatorname{sim}$ & sim & กล̃̃o \\
\hline \multirow{5}{*}{8} & 8.1 & Representaçāo gráfica do escopo (3) & กẫo & กล̃o & กล๊̃o & กã̃o & nẫo & não \\
\hline & 8.2 & Ajudar a relacionar termos [3] & กลิ๊o & กã๊o & กã๊o & nẫo & กว๊̃o & กล̃o \\
\hline & 8.3 & Categorizaçäo com base no conceito [ 3 ] & กล๊̃o & กล๊̃o & กล̃o & กẵo & กล̃o & กล̃o \\
\hline & 8.4 & Ajudar a definir os conceitos [3] & $\operatorname{sim}$ & กลิ๊o & กã̃o & กã̃o & $\operatorname{sim}$ & กẫo \\
\hline & 8.5 & \begin{tabular}{|l|l|l} 
Características de Divisăo [3] \\
\end{tabular} & กẫo & nẫo & nẫo & nẫo & กão & กằo \\
\hline
\end{tabular}


Cabe ainda ressaltar que os softwares avaliados apresentam algumas características positivas, que embora não tenham sido consideradas isoladamente como requisitos nesse trabalho, merecem destaque. Dentre elas, selecionamos as que julgamos mais relevantes, as quais exemplificamos com algum dos softwares analisados que possuísse a característica em questão: (i) recursos de busca sofisticados incluindo linguagens de busca baseadas em SQL2 que permitem recuperações poderosas, talhadas para o mecanismo de banco de dados que armazena o tesauro (Thesmain); (ii) adaptação do software sob medida e sem custo para atender pequenas demandas do usuário (Synaptica); (iii) suporte a múltiplos tipos de dados e a inclusão de imagens (Termchoir); (iv) facilidades de uso tais como recursos de clicar e arrastar e menu adicional sensível ao botão direito do mouse (Termchoir); (v) A possibilidade de escolha entre duas versões de normas padrão, sendo elas a ISO 2788 para tesauros de assunto e a AS4390/ISOI 5489 para taxionomias (TermTree); (vi) A possibilidade de salvar os dados de configuração de relatórios, como por exemplo a ordem e tipos de relações a serem impressas (Multites).

Por outro lado, também existem alguns aspectos negativos que pudemos observar. Por exemplo: (i) o Multites não permite gerar um relatório sistemático único com hierarquia de gênero-espécie e parte-todo; (ii) não se conseguiu desfazer o relacionamento de USE/UP no Termtree; (iii) o TemaTree não possui um programa instalador, podendo ser difícil de instalar para usuários com pouca familiaridade com informática.

Funcionalidades ou limitações como às exemplificadas acima existem em vários dos softwares avaliados, sendo que o Termchoir é o que mais recursos oferece e o TemaTree o mais limitado. Em contrapartida, quanto mais recursos são adicionados em um software, geralmente mais complexo fica o seu uso. Os requisitos que apontamos nesse trabalho, têm como objetivo fornecer um guia para ajudar na avaliação de softwares de tesauro, mas eles são sintéticos, e, desta forma, não vão por si só avaliar o quanto um software é mais poderoso que outro em relação a um mesmo requisito, e qual a complexidade introduzida por conta disso. Por exemplo, a maioria dos softwares avaliados fornece recursos para importação de dados, porém alguns fornecem opções mais flexíveis e poderosas, e também mais complexas, do que outros, incluindo até a possibilidade de elaboração de scripts ${ }^{3}$ para configurar essa tarefa. Não é o objetivo desse trabalho avaliar qual o melhor software, mas sim apontar quais os requisitos mínimos para que o software seja considerado adequado. Dessa forma, a análise mais detalhada sobre como cada software explora cada requisito não foi abordada em profundidade. Até porque, para a avaliação do melhor software depende do objetivo que se pretende atingir. Por exemplo, se o que se deseja é construir um tesauro simples, talvez a escolha mais adequada seja uma ferramenta com os requisitos mínimos e sem muitas funcionalidades adicionais que dificultem a sua operação. Entretanto, cabe observar que os requisitos aqui apontados podem ser estendidos para uma análise mais aprofundada, ou ainda, notas podem ser atribuídas no lugar de sim ou não, no julgamento de cada requisito. Neste caso, deve-se ter o cuidado de estabelecer parâmetros para a atribuição de uma nota, de forma a diminuir a subjetividade na avaliação.
2 SQL é uma linguagem padrão para acesso e manipulação de bancos de dados.

${ }^{3}$ Um script aqui é considerado como um conjunto de instruções, em formato texto, utilizado para realizar alguma tarefa configurável, ou seja, que possa alterar algum aspecto de uma funcionalidade já pronta dentro do software, através de uma interação com este. 


\section{Conclusão}

Atualmente os tesauros vêm ocupando posição de destaque como elemento central para organizar e divulgar informações, em um mundo onde a quantidade e variedade de dados têm criado dificuldades para a sua manipulação e resgate. Estes tesauros, muitas vezes extensos e com uma ampla rede de relações entre seus termos, requerem o uso de ferramentas e metodologias que venham apoiar a sua elaboração, tarefa que está longe de ser trivial.

Neste contexto, acompanhando a evolução da tecnologia de computação, os softwares voltados para a construção de tesauros surgem para suprir a demanda de diminuir a complexidade da tarefa de criação, armazenamento, atualização e divulgação dos vocabulários concebidos. Entretanto, ao que parece, não existe a preocupação no software de se explicitar o conhecimento tácito que o construtor do tesauro deve possuir. As ferramentas, até onde pudemos avaliar, não estão preparadas para representar ou guiar o processo de modelar o domínio de conhecimento abordado pelo tesauro. Ao contrário, seu foco é automatizar as tarefas operacionais, e, nesse caso, as ferramentas estão bem preparadas para fornecer recursos como: criar o termo, associar a este uma relação, armazenar em banco de dados, emitirem relatórios, e assim por diante. Entretanto, quando se aborda a questão da concepção do tesauro, do seu pensar, então a realidade é outra: nenhuma ferramenta provê recursos para expressar a modelagem do domínio, para planejar suas relações em mais alto nível, ou para guiar a categorização dos termos com base em seu conceito, o que parece indicar uma visão dissociada entre a tecnologia e as metodologias.

A concepção do tesauro pode ser considerada a parte mais complexa da sua elaboração, e hoje tem sido a fase que antecede o uso das ferramentas, talvez pela lacuna metodológica deixada por estas e apontada neste trabalho. É nessa fase que o escopo é traçado, os relacionamentos são pensados e o tesauro toma sua forma, provavelmente na memória tácita e em materiais de apoio usados pelo seu criador.

Nesse sentido, uma verdadeira inovação, que esperamos ser percebida pelos desenvolvedores de software de tesauro é uma visão integrada, onde aos aspectos operacionais venham se juntar os aspectos metodológicos criando uma ferramenta mais inteligente.

\section{Comparative Study of Thesauri Softwares}

To help the construction of vocabularies, the use and the consequent selection of a thesaurus construction software is a must. However, thesauri softwares have different characteristics of functionalities, costs, and methodological support, among other diversities, which must be carefully analysed according to the goals and complexity of the thesaurus to be built. Thus, this work aims at introducing a comparative study of thesauri software, taking into account present thesauri uses.

Key-words: Thesaurus software; Evaluation software 


\section{Referências}

ACTIVE CLASSFFCLAION SOLUIIONS. Termtree. Disponivel em: < hittp://www.termtree.com.au > Acesso em: 06 jun 2005.

CAMPOS, M. L. A. Linguagem documentária. Niterói: EDUfF, 2001.

DAHLBERG, Ingetraut. Teoria do conceito. Ciênncia da Informaçãa, v. 7, n. 2, p. 101-07,1970.

FERREIRA, D. Tematres.Disponivel em: < hittp://wwww.IO20.com.ar/tematres/index.html > Acesso em 6 jun. 2005.

GAMZMANII, J. Criteria for the evaluation of thesaurus software. International Classification, v.17, n. 3/4, p. 148-157, 1990. Disponivel em: < hittp:// www.willpower.demon.co.uk/ganzmann.htm > Acesso em 6 jun. 2005.

GEMEI. General Environmental Multilingual Thesaurus, 2005. Disponivel em: < http://wwww.eionet.eu.int/gemet > Acesso em 6 jun. 2005.

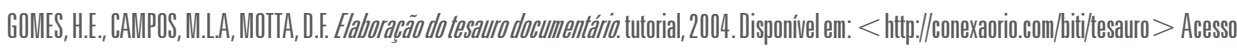
em 6 jun. 2005

ISO 5964. Guidelines for the establishment and development of multilingual thesauri, 1985. Disponivel em: < http.//www.iso.ch/iso/en / CatalogueDetailPage.CatalogueDetail?CSMUMBER $=12159>$ Acesso em 6 jun. 2005.

LAMCASTER, FW. Vocabulary Control for Information Retrieval. 2.ed. U.S.A.:IRP,1986.

MICROSOFT Corporation 2005. Disponivel em: < hittp://microsoft.com > Acesso em 6 jun. 2005.

MILSTEAD, J. L. Use of thesauriin the full-text environnment.Indian Head, MD, The Jelem Company, 1998. Disponivel em: < hittp://www.bayside-indexing.com/ Milstead/useof.htm > Acesso em 6 jun. 2005

MULSYSTEMS. Multites. Disponivel em: < hittp://wwww.multites.com > Acesso em 6 jun. 2005.

ORACLE Corporation 2005. Disponivel em: < hittp://www.oracle.com > Acesso em 6 jun. 2005.

RAMGAMATHAIl, S.R. Prolegomena to library classification. New Delhi: Ejnar Munksggaard, 1951.

SILVEIRA, M. de L. Recuperaçãa verticaldde informação. um estudo de caso na area jurídica. Tese (Doutorado) - Universidade Federal de Minas Gerais, Belo Horizonte, 2003.

SOERGEL,D. Thesauri and ontologies in digital libraries: tutorial. In: European Conference on Digitallibraries(ECDL 2002), Rome, Italy, 2002. Disponivel em: $<$ hitpp://www.dsoergel.com/cr/B63_rome.pdf > Acesso em 6 jun. 2005.

SYMAPSE CORPORATION. Synaptica. Disponivel em: < hittp://www.synaptica.com > Acesso em 6 jun. 2005.

UMWEELIBUNDESAMI. Thesman. Disponivel em: < hittp://www.umwelthundesamt.at/umweltdaten/produkte/superthes > Acesso em 6 jun. 2005.

UNESCO. Guidelines for the establishment and development of monolingual thesauri.Paris, 1973.37p.

WEBCHOIR . Termchoir.Disponivel em: < hittp.//www.webchoir.com > Acesso em 6 jun. 2005.

WERSIG, G; IEVVELING, U. Terminology of Documentation.Paris: Unesco, 1976.274p.

WILL, L., Software for huilding and editing thesaluri, 2005. Disponivel em: < hitp.//www.willpowerinfo.co.uk/thessoft.htm > Acesso em 6 jun. 2005. 